\title{
Some Observations on the Concert Audience
}

BECAUSE THE PURPOSE OF THIS PAPER IS RATHER COMPLEX, AND BECAUSE limitations of space have made it perhaps too concise-gnarled, I fearI thought it best to begin with a group of attitudes, assumptions, theses which might help to explain what I am about.

First, I am struck (and a little troubled) by a confusion in the meaning of the word "mass." In a good and recent article, Roy Harvey Pearce 1 argues for a healthy relationship between popular art and both folk and elite art. He would have us leave the way open for gifted people to move from one to another: "My Fair Lady to Pygmalion; advertising layout to Mondrian; Paddy Chayefsky to Chekov; Ted Williams to Nick Adams." 2 But the limitation of this article for the student attempting to define the place of the arts in American culture is that, at least to some extent, $\mathrm{Mr}$. Pearce confuses mass culture with $a$ culture under the influence of the mass media. He says that ours is the society in which mass culture "has taken deepest root." 3 What we have here is a case of unintentional equivocation. Ortega y Gasset's mass man is defined as "unthinking" man; in the work of semi-pro sociologists like Mr. Pearce (and myself, or any of us who take a fling at drawing large-scale social conclusions on the basis of our competence in our own fields and our subjective understanding of others), this mass man has become confused with "man in a room with a TV set"- that is, "man under the influence of the mass media." The two are not in every way identical. Indeed, as we shall see, the two different uses of the word "mass" are derived from two sharply contrasted models of social structure.

Confusion of a related sort appears even in the works of those who should know better. Daniel Bell, in his splendid critique, "The Theory of Mass Society," 4 says that he doubts that western civilization can properly be understood as "mass." To make his point, he turns to an examination of American society, citing that tendency, noted by Alexis de Tocqueville, to be a nation of "joiners," and such phenomena as the

1 "Mass Culture/Popular Culture: Notes for a Humanist's Primer," College English, XXIII (March 1962), 417-32.

4 Commentary, XXII (July 1956), 75-83.

3 Ibid., p. 424. 
surprising growth and proliferation of small newspapers. Evidence of this sort suggests that he is dealing with the word "mass" in its implications of sameness; the vigor of voluntary associations of various sorts is taken to indicate that in a world situation in which other peoples have felt themselves "lost," Americans have been able to "find" themselves by achieving status within the limits of smaller groups of their own invention. It also offers documentary evidence for the contention of liberals recently that ours is a pluralistic society, and indeed that it is this pluralism that we are fighting to maintain in the Cold War. ${ }^{5}$

Mr. Bell goes on to argue that since change is our norm, ". . . those consequences of change predicted by theorists basing themselves on European precedent find small confirmation." This is an extremely important point. Historians of immigration like Oscar Handlin have long argued that if there is a determining characteristic in the American personality, it is probably less the result of those frontier influences which Frederick Jackson Turner limned out than it is of that one basic trait which every immigrant almost by definition shared: something was drastically wrong with his position in the society which he left. Otherwise he would not have left. From these premises, it is possible to develop a theory of American personality based on a national capability to live with insecurity, change and social mobility. We often say of politically unstable countries that they are "not ready for a democracy"; it may be that it would be more accurate for us to say that since every new freedom brings a new insecurity, they are not yet accustomed to living with insecurity. At our best, on the other hand, we, in e.e. cumming's words, "wear the dangerous looseness of doom and find it becoming."

Curiously, having argued that American society is not "mass," and that this may be best seen by comparing it with European society, Bell ends his article by repeating that he doubts that western civilization is a mass civilization. As nearly as I can make out, what he has demonstrated, and rather convincingly, is that American society and the American social structure are radically different from what exists in Europe. Ortega y Gasset saw society as composed of a small elite with elite values and a large mass with "mass" values; the threat was that as "mass" man broke down the barrier between the two groups, he destroyed an elaborate traditional framework in many ways admirable. I doubt whether this analysis of the situation fits the American experience.

A second controlling assumption in the discussion of the concert audience which follows is this: it is a truism (or it should be) in American

5 See, for example, Arthur Schlesinger Jr.'s contribution to “The Cold War and the West: A Symposium," Partisan Review, XXIX (Winter 1962), 77-81. 
Studies that each field must be treated in its own terms, and that each field is in some ways peculiar. For example, if one treats an art only in cultural terms, one does violence to the art. As Kenneth J. LaBudde pointed out in a recent article, the naïve notion of interdisciplinary study which seemed to be a guiding force in the early days of American Studies seems pathetic in retrospect.

The correlation seemed so evident. One could perhaps show on a screen a slide of a painting such as Alexandre Houge's "DroughtStricken Area." . . . At the same time one could play a recording of Woody Guthrie's "Dust Bowl Ballads." Now if one were really a frustrated producer, one could, I suppose, play the record softly as background music to one's reading aloud from The Grapes of Wrath. ${ }^{6}$

Proceed in this manner and all three works of art suffer. This is not to say that interdisciplinary discussion is impossible; certainly the cultural milieu out of which a work of art grows is important to an understanding of it, and if two or more arts seem to be reacting to the same cultural forces, the interdisciplinarian is probably onto something. But if he ever loses sight of the fact that changes in the different fields are not merely a reaction to historical and cultural tendencies, but also to the historical and purely artistic development of the individual field, he is clearly oversimplifying and cheating. I would be the first to agree that abstract expressionism in painting and atonalism in music bear some common relation to social conditions in our century, but I would also insist that they can be accounted for in terms of the development of each art: it is a cliché of music history that Schoenberg represents a logical step beyond Wagner; similarly, one could trace the artistic ancestry of Franz Kline back to tendencies in late-nineteenth-century French painting.

A third assumption: I will take the position that it would be a Good Thing if composers had a large and lively audience for their music. My work in this area began as an attack on music critics' ideas about how to enlarge the concert audience. It therefore seems reasonable to retain their concern; after all, it would be nice to have a big audience.

Social critics earlier than de Tocqueville and more recent than Ortega y Gasset have concerned themselves with the place of the arts in a democracy and, being a notoriously self-conscious people, Americans have taken them seriously. In the field of concert music in particular those who would like to help the cause of the art have been far too willing to take

6 "Regionalist Art and American Studies," Journal of the Central Mississippi Valley American Studies Association, II (Fall 1961), 49-65, 57. 
the warnings of such experts at face value, without careful examination of the peculiarities of the situation. It is, to select an obvious analogy, as though economists attempted to account for the American economy in purely Marxist terms, without considering the limitations of Marx' formulation, the surprising flexibility of American governmental institutions or America's apparent social fluidity.

If we look at the matter closely, we can see that the problem which most worried Ortega y Gasset-that is, that newcomers to the arts would pollute tastes because they do not bring with them the proper values-is not really relevant in the concert hall. While it is true that in the nineteenth century popular taste in the United States to a considerable extent did corrupt concert music (and examination of any of the volumes of memoirs written by barnstorming virtuosi will bear this out), it is also true that we did not have at the time a concert audience large enough to be worthy of the name. Whether they knew it or not, the barnstormers were functioning as popular entertainers. And what is more, the situation in the twentieth century is totally different. If anything, composers have been hampered not by too much audience influence, but by too little.

The special problem of music (and this is an over-simplification) is that for the first time in the modern world the composer in the early part of this century got too far ahead of his audience. Composers have been shocking audiences for centuries, but the gap between audience and composer certainly was never so great as it was then. A sign of its magnitude is that in this century we have had the unusual phenomenon of major composers writing music with no specific performance, commission, prize competition or artist in mind. The composer, deprived of that immediate audience reaction which, whatever its disadvantages, is an essential part of any healthy art, retreated to his garret, from which generations of philanthropists, propagandists and musical reformers have attempted to rescue him. They still concern themselves with vigorous windmill-tilting and assaults on dead horses. They are worried, for instance, about listener comprehension of the new music; this is no longer a serious problem: decades of movie and television sound-tracks have conditioned us to accept, even to "understand," almost anythng which the composer is likely to do.

It is revealing to compare what happened to the concert audience in the fifty years from 1900 to 1950 to what happened in jazz in the ten years beginning, let us say, with 1943. The situations are surprisingly similar. Some time during the Second World War, for reasons which are partially social and partially a matter of a logical development of their art, the front line of jazz performers lost touch with the audience. In a very brief time, these men reached a position so far ahead of what their 
listeners could comprehend that the music which they were producing seemed as mad to its listeners as did the music at those famous concerts early in the century which produced riots and flying vegetables. It took roughly ten years for an audience to catch up with what the bopsters had done, and, just as the various directions in which the concert musical rebellion at the turn of the century were woven together in a synthesis usually called the International Style, the developments in bop were assimilated into the fabric of what came to be known as Modern Jazz. Jazz reached a workable solution to its audience problem in ten years as compared to the fifty it took concert music. It has as yet been unable to solve the problem of patronage.

Concert composers are a little better off: the universities have taken over the job which the eighteenth-century patron and the nineteenthcentury concert audience used to perform, so that by now the garret has been transformed, by and large, into a poor man's split-level in a faculty slum. Critic and crusader, however, go on undaunted, believing that all it takes to restore the composer to his rightful position (whatever that is supposed to be-no composer in the last two centuries, to my knowledge, has ever been able to support himself solely on the proceeds earned from music written for the concert hall, though a few have managed if they wrote music for the stage) is propaganda for the new music aimed at some hypothetical established body of listeners.

The facts are that the special reasons for the failure of the new music to hold a large audience are unrelated to this line of thinking. They are simple, almost physical, and they are peculiar-to this one art. I will list them briefly.

1) The new music, of whatever variety or quality, is music of great tension and demands careful listening. It will not work (as much of the good music of the past will) as fashionable background to a cocktail party. You can't even read to it. And since few people, even serious music-lovers, really spend more than a few minutes a week listening intently, it does not get listened to in the home.

2) If it is any good, it works very well in the concert hall, even when performed for musically unsophisticated audiences. But concert managers are afraid of it. They believe that it frightens away audiences, and, what is worse, they know that it is terribly expensive to perform. The cost shows up less in royalties than in rehearsal time; if you study the programs of the major orchestras, you discover that the appearance of a new work on a program usually means the appearance of a thundering herd of war-horses in the programs surrounding its performance. New works take extra rehearsal time; rehearsal time is frightfully ex- 
pensive; all orchestras are broke. So the new piece must be padded about with works from what orchestra librarians call "the first repertoire," works which can be played with little or no rehearsal.

Moreover, any work, new or old, takes repeated listening to establish itself; very few new works, even most of those which the critics take to on first hearing, are ever re-performed. The late Serge Koussevitsky had a deserved reputation as a "pioneer." 7 Under him the Boston Sym. phony premiered an impressive number of new works. But if one reads back through the program books of the Symphony, one quickly discovers that most of the new works performed were played once or twice, then forgotten.

\section{FIGURE ONE: WORKS BY CONTEMPORARY AMERICAN COM- POSERS PERFORMED BY THE BOSTON SYMPHONY UNDER KOUSSEVITSKY UP TO 1949}

\begin{tabular}{|c|c|c|c|c|c|}
\hline Composer & $\begin{array}{l}\text { Number } \\
\text { of works }\end{array}$ & Repeats & Composer & $\begin{array}{l}\text { Number } \\
\text { of works }\end{array}$ & Repeats \\
\hline Barber & 6 & 2 & Gershwin & 3 & 0 \\
\hline Bernstein & 2 & 0 & Griffes & 3 & 2 \\
\hline Bloch & 11 & $9 \bullet$ & Hanson & 6 & 2 \\
\hline Copland & 13 & 5 & Harris & 7 & $5 * \bullet$ \\
\hline Cowell & 2 & 1 & Loeffler & 12 & $32^{\bullet}$ \\
\hline Diamond & 2 & $\mathbf{0}$ & Piston & 11 & $1 \cdots$ \\
\hline Fine & 1 & 0 & Schuman & 5 & 3 \\
\hline Foss & 3 & $\mathbf{0}$ & Sessions & 1 & $\mathbf{0}$ \\
\hline Foote & 2 & $0^{\bullet}$ & Thomson & 3 & 1 \\
\hline
\end{tabular}

- Perhaps these should not be on the list. They belong to an older generation, and Bloch is an immigrant.

- The Third Symphony, played thrice in 1939, repeated the same year in a special concert, and then in 1941 and 1949. This work is always spoken of as a sensationally successful exception to the rule that new pieces are not popular.

*. Up to 1949, not one symphony repeated in a subsequent season.

7 John H. Mueller in The American Symphony Orchestra (Bloomington, Ind., 1951) points out a possible reason for the surprising courage shown by conductors in America. He says that in this country there was a wider gap in sophistication between audience and conductor than in Europe. The first major American conductors were Europeans who brought with them nineteenth-century German romantic ideals; orchestral management and orchestral audiences were more likely to hold the conductor in awe and to accept as standard opinions of those "in the know" ideas which were, in fact, avant-garde. The result, according to Mueller, is that if one compares American symphony orchestra programs of the period to those in Europe, one discovers that American concertgoers were listening to "heavier" and more experimental programs than were their European counterparts. It would seem, then, that Koussevitsky was working in an established tradition. Americans expected the conductor to blaze the trail. It is also worth observing that Ortega y Gasset's fear seems once again unjustified; if anything, these early concert audiences seem to have been too timid about imposing their own tastes. 
3) And this is our main point today: it is my thesis that if we examine the listening career of the individual music lover, we find that a taste for the new music is usually the last taste he acquires, if he acquires it at all. I believe that the concert audience is pyramidical in structure, and that tastes are dynamic, not static. As one moves upwards from the base of the pyramid, where tastes are limited to the familiar chestnuts and the best-known music of the best-known composers, the ranks of the audience thin out. The new music, alas, occupies a position near the apex.

If these assertions are true-and I hope to demonstrate that they arethe way to get more listeners at the apex would be to enlarge the pyramid: before there can be more customers for the product which the avant-garde is selling, we must get more traffic in the store. How do people come to like concert music? How large is the audience?

Much of what little reliable data we have on this latter topic comes from a series of studies financed by the American Federation of Musicians in the years following the Second World War. While these data are limited in many ways and certainly out of date, they at least indicate unambiguously that the concert audience, however defined, is growing.

FIGURE TWO: CASH OUTLAY FOR ADMISSIONS TO MOTION PICTURES COMPARED TO THAT FOR CONCERTS, OPERAS AND LEGITIMATE THEATER (in millions of dollars)

$\begin{array}{ccccc}\text { Year } & \text { Movies } & \text { Index } & \text { Concerts, etc. } & \text { Index } \\ 1939 & 659 & 100 & 32 & 100 \\ 1940 & 709 & 107.6 & 36 & 112.5 \\ 1941 & 756 & 114.7 & 40 & 125.0 \\ 1942 & 924 & 140.2 & 48 & 150.0 \\ 1943 & 987 & 149.8 & 68 & 212.5 \\ 1944 & 1175 & 178.3 & 82 & 256.2 \\ 1945 & 1359 & 191.0 & 80 & 250.0 \\ 1946 & 1427 & 216.5 & 91 & 284.4 \\ 1947 & 1380 & 209.4 & 103 & 321.9\end{array}$

Limitations: 1) Since the figures are based on admissions receipts, records and radio are specifically excluded. 2) The "concert" figures include receipts for admissions to plays. 3) The figures stop at the beginning of a great boom in concert music triggered by the long-playing record and the high-fidelity craze. 4) The movies in 1947 provide a poor basis for comparison; they were just entering a brief period of declining receipts. Source: International Musician, December 1948.

How fast it is growing I do not know. It is discouraging to note that its size until about the period of the A. F. of M. study was a steady 1 per cent of the total population: it kept pace with population growth but seemed unable to engage a proportionally larger group. I am prone 
to trust those rather subjective indices, the mass media, which, in the years since the study, give one the distinct feeling that the rate of growth has finally increased; I think that something which one wants to label "common sense" tells us that increased leisure means increased audience, but of course one should be wary of common sense when dealing with social and cultural issues. For our purposes, it hardly matters anyway, since even were the audience merely keeping pace proportionally, it would still be growing. If it is growing, new listeners must be coming from somewhere. Where?

Here is another list: six hypothetical "paths" to the concert hall. First: undoubtedly many people inspire a taste for good music simply because it is present in the atmosphere of the homes in which they are brought up. If one reads the music critics, particularly the big ones in the eastern papers, and especially Virgil Thomson, one soon learns that most of them tacitly assume that all sophisticated listeners come from this source. That most people agree with them can be inferred from the aura of snobbism which surrounds the concert hall; the assumption is that "our kind of people" like good music; these critics are distinctly writing for "our kind of people." If you are not "in," you are "out," and your snickers only demonstrate how real you think the difference is. ${ }^{8}$ But the idea that this process, which we can call "the traditional path," is the only way to the concert hall is absurd, first, because it presupposes a more rigid class structure than we have; second, because, as we have seen, the concert audience is growing, and the hypothetical social class to which this group of critics thinks it is addressing itself is precisely that class which students of population and fertility tell us is unable to keep pace with rapid population growth. This explanation would make sense were our society clearly split between "mass" man and "elite" man. But, as we have seen Daniel Bell argue, it is not.

If we return to the International Musician and the A. F. of M., we can discern the outlines of a second path to the concert hall (and we should make clear from the outset that these paths overlap and intertwine). According to that magazine, as of 1948, one out of every eight Americans played a musical instrument, and the author of the article in which this figure was reported goes on to say that it is "axiomatic that the audiences for professional performances of all types, popular and serious, are recruited at least fifty per cent from amateurs who have taken a fling at playing an instrument." One would like to know where on earth the author came up with his figure, but his point is certainly well taken.

8 John H. Mueller's The American Symphony Orchestra contains a good discussion of such non-musical attractions-social prestige and civic pride, for example. 
Certainly amateurs pick up an interest in music from playing. But if we examine the type of music which they play, we discover some interesting facts: most amateurs who participate in instrumental playing belong to bands; almost all band music is what we will later define as standard music. Those who do not for the most part also play standard musicpopular songs which have become "standards," light classics, old favorites, popularized versions of the more familiar classics. This is easy enough to document; one has merely to examine the selections included in elementary and intermediate music instruction books for the various instruments. ${ }^{\circ}$

Then I suppose that one should map a third path, that taken by those attracted to music by the hi-fi craze. The totally naïve listener who buys a rig has to buy some records. Presumably he starts with pops-the hit parade-but if he wants to show off his device, he has to buy LPs. Since most LPs are not really pops-the hit parade comes out on 78s and 45sand since he will soon tire of recordings of sonic boom and cannon, the chances are good that he too will turn to standard music. Perhaps this is as far as he will ever get: 101 Strings and no content. But he may get farther.

Yet a fourth path is that of the music appreciation industry (or "racket," as one hostile critic calls it) and music education; I group them together not to imply anything about their relative merits but for convenience and brevity. I have no idea of the ultimate effectiveness of compulsory music education - the so-called "appreciation" courses required in many school systems-beyond the subjective reports of friends and students who have gone through them. They say that generally such courses are ineffective except in the cases of students already highly motivated to learn about concert music.

Motivation, which would seem to be the critical element in the grade and high schools, certainly is the critical element on the college level. What is going on is perhaps best understood in terms of reference-group theory. ${ }^{10}$ If we pick the brain of a hypothetical serious minded student

$\theta$ The reasons are easy to understand. Concert selections are too difficult for the beginner (unless they are simplified, in which case they are best understood as standard music); popular songs are carefully protected by law and extremely expensive to quote. What is worse, their popularity disappears so quickly that one would have to bring out a new edition of one's book every three weeks.

10 This is a useful sociological concept designed to enable one to pin down the sources of ideas, ideals, attitudes, value-judgments, etc., by discovering from which groups the subject has acquired them, against which groups, in other words, he is measuring himself. If one were studying a group of students, for example, one might expect to find among their important reference groups their peers, their parents, their teachers, members of professional or fraternal groups, and so forth-any group to which the subjects might "refer" themselves. 
and attempt to discover what he wants to get out of college, I think that we will find that, besides specific or specialized training, it is something which can be defined, albeit vaguely, as an understanding of matters which people he admires or would like to imitate care about. A recent exploratory study of reference groups on a large campus, besides demonstrating that it is almost impossible to pin down a subject's reference groups without the sort of prompting which gives the gag away and invalidates the study, did suggest something of the sort. If the people to whom the student in one manner or another "refers" himself are interested in good books, art and music, he feels that he should know enough about such matters to enjoy them himself and/or to be able to talk about them. Most of us are, I believe, aware of how common this attitude is, especially among our better students.

Presumably, if the student does not pick up the requisite information socially or through required courses, he will go out of his way to acquire it. He is thus using whatever course he takes to equip himself for what is probably best understood as a change in social class, although he himself, perhaps through double-think, does not refer to class. "Educated," "intelligent," "sensitive," "knowledgeable," "people who count": these are the ways the students describe those they wish to emulate; they do not use the term "upper class," probably because this would imply a lack of democratic feeling and an acknowledgement of their own inferior class position at the present. If classes in our society should be understood not merely in terms of cash income but also in terms of style of life (which includes tastes and interests) and if, as also seems obvious, the college is for a great many students a place in which to cast oneself in the mold of a desired level of society, it would not be surprising to find students using introductory art and music courses for social purposes. (I should make clear that I am neither applauding nor criticizing the process; I do not want to imply anything about the sincerity of the student's commitment to the arts.) ${ }^{11}$

Moreover, motivation of this type would seem also to account for the prosperity of the do-it-yourself culture industry. The magazines are full of invitations to join clubs which offer a quick introduction to the better things in life; all such advertisements stress the "informative booklets by well-known authorities" which accompany each selection. The entire

11 It is, indeed, possible to argue that their commitment to the arts is of the best possible sort. Russell Lynes, for example, praises the enlightened dilettante, whose enthusiasm is genuine, and who encourages "a high degree of performance in whatever field of interest happens to be his." He can "determine the quality of our culture." "Time on our Hands," Harper's Magazine, CCXVII (July 1958), 34-39. 
come-on is quite consciously designed to suggest that the club offers answers to the question which the novitiate wants answered: How can I learn about those things which people I want to be like talk about?

But I am convinced that by far the most worn path to the concert hall runs through that music most despised-and perhaps deservedly so-by critic and connoisseur, so-called "standard music." By this I mean such things as "all-time favorites," popularized versions of the classics, "popular classics," the sound of Muzak and other sonic wallpaper, Kostelanitz, Waring and even Liberace: in short, all that "middle-brow slush and slop" which music historians have found aesthetically less interesting than pops, rock and roll, hillbilly and even rock-a-billy, and compared to which the Twist is an artistic movement of great significance.

I have some sketchy evidence to support my assertion, and hope soon to obtain more. First, we may examine more of the data gathered by the A. F. of M., this time printed in the International Musician for June 1948.

FIGURE THREE: AMERICAN HOMES IN WHICH AT LEAST ONE PERSON SAYS THAT HE ENJOYS A GIVEN TYPE OF MUSIC, BY SECTIONS

$\begin{array}{lccccc}\begin{array}{l}\text { Section } \\ \begin{array}{l}\text { Type of } \\ \text { Music }\end{array}\end{array} & \text { EAST } & \text { MID-WEST } & \text { SOUTH } & \text { WEST } & \text { OVER-ALL } \\ \begin{array}{l}\text { Church } \\ \text { Music }\end{array} & 44.0 \% & 63.4 \% & 74.3 \% & 57.6 \% & 60.8 \% \\ \begin{array}{l}\text { Old } \\ \text { Favorites }\end{array} & 53.3 & 58.0 & 51.4 & 54.4 & 54.4 \\ \begin{array}{l}\text { Semi- } \\ \text { Classical }\end{array} & 49.8 & 44.9 & 28.2 & 52.5 & 42.3 \\ \text { Classical } & 40.2 & 32.9 & 22.1 & 45.8 & 33.3\end{array}$

Limitations: 1) These figures do not give a clear indication of number of listeners. 2) The categories selected seem badly designed for our purposes. What we have called "standard music" includes both what the chart calls "Old Favorites" and "Semi-Classical." 3) A good many people unfamiliar with concert music call Johann Strauss "classical." Indeed, they would also include Mantovani. If the tune in question is twenty years old, there are "strings" in the orchestra, and the thing has been played in Carnegie Hall (even once), or has some snob appeal (some of their friends call it "longhair"), they think of it as "classical." Curiously, on this level of understanding, no music is called classical if it has lyrics. It is because of such misunderstanding of these terms that in my own work I use the term "concert music" instead of "classical music," and concern myself with the listening history of people who are already initiates. 
Whatever their limitations, these figures suggest that there exists a connection between interest in standard music and interest in the classics. Where the figures for "Old Favorites" and "Semi-Classical" are high, so are those for "Classical"; the low figures also coincide. If we lump together the two standard categories (in which cases the figures can no longer be called percentages, but have rather to be termed "indices"), this becomes even more apparent. The index for the eastern U.S. would be 103.1; for the Mid-West, 102.9; the West, 106.9; but in the South, only 79.6.

In all fairness we should point out that these figures could be accounted for in terms of the "traditional" notion about the sources of the concert audience. If musical tastes follow solidified class lines, there may simply be more members of the "properly established classes" in those areas which score high. But I find this implausible: it is based on an hereditary conception of class inapplicable to this country. Our class lines are far too fluid, especially if we consider class as partially a matter of tastes.

Some years ago I conducted a very limited and statistically unsound study of my own, designed to determine something about the listening careers of people from near the top of the audience pyramid. I hope, in 1964, to try it again, still on a limited scale, but this time with a welldesigned universe and adequate controls. My respondents the first time were subscribers to the program guide of a concert music station who were also, first, regular listeners to my radio program, and second, interested in the new music. The questionnaire, which I plan to use in the second study as well, reads as follows:

Many people come to like concert music because it was important in the homes in which they were brought up; others come to like it through a long, slow process of taste development. Undoubtedly there are many other routes to the concert hall. This questionnaire is designed to determine what path you followed.

\section{Background}

A. Would you say that you were brought up in a "musical" home? That is, was there an active interest in music, something more than a feeling that it would be nice if the children studied a little piano?

B. Did you ever play a musical instrument? If so,

1. What instrument?

2. How seriously?

3. Ever play in an orchestra, band or recital?

4. Do you play now?

(Please elaborate where necessary; the more detail the better.) 
II. Present activity
A. How many concerts a year, on the average, do you attend?
B. Where do you go to hear concerts? 12
C. In order of preference, would you rather hear orchestral, operatic or chamber music? If you can't make so simple a choice, please elaborate.
D. Do you prefer programs which include contemporary music?
E. Do you have a record collection? What sort of music predomi- nates?

III. Development of tastes

A. Do you now, or did you once like

NOW ONCE NEVER LIKE LIKED LIKED

1. Jazz (of any sort)

2. Popular music-that

is, the "hit" songs

3. Standard music [a description

of what was meant by "standard music" was given]

B. What was the first piece of "classical" or concert music which you can remember liking? If you can't bring back a specific work, say something about the kind of music it was.

C. In the order in which you developed a taste for them, list the kinds of concert music which you have liked since that type described in the previous question. If you can, name a work or two in each type to give us a clear idea of the sort of music you mean.

\section{Comments}

If our questions in any way do not fit your case, or if you can further clarify anything you have said above, please use this space to explain.

The decidedly long-haired respondents to my first small survey had, in every case, at one time preferred standard music. According to their age, they named such favorites as Freddy Martin (he of the popularized arrangements of tunes borrowed from Tschaikovsky), Fred Waring or Montovani; according to their experience in performance, they named simplified arrangements of familiar classics for their instruments, or band music. And the first piece of concert music they could remember liking

12 This question was included for reasons unrelated to our main point in the present paper. A study done at Brown University a few years ago revealed the surprising fact that listeners apparently go to favorite halls more because there is a concert at the hall than because of a favorite type of music which is being played. 
was invariably a work like the Rachmaninoff Second Piano Concerto (which we may call "mama"), Gershwin's Rhapsody in Blue (which we may call "papa"), the Warsaw Concerto (which one waggish critic called the bouncing baby offspring of the first two works), a Tschaikovsky symphony or the 1812 Overture, Scheherazade: in short, those serious works in the most immediately accessible romantic tradition, and exactly those works most copied in standard music arrangements and rifled through for themes for pop songs.

It would seem, then, that the best plan for the crusaders for the new music to follow would be to "lay off" their favorite targets, standard music and the warhorses, and to concentrate instead on helping nature take its course. It is easy enough to see practical ways in which this can be done. For example, when the Montovani orchestra (perhaps "organization" would be a better word) made its American tour a year or so ago, it would have been helpful had a few serious music critics in different cities attended and reported. They would not have had to lower their standards in any way. An honest description of what went on would have sufficed to make clear to those who attended the concert just what the music they were listening to represented, and even to suggest to them that the "real thing" might be preferable. Similarly, an understanding of the manner in which listeners get to the concert hall might give the programers of educational concerts clearer principles on which to select works. I have played hundreds of educational concerts, and can report that school children are bored by most of the stuff performed at them. But they respond well to what musicians call "real rousers"-melodic and emotional late romantic music, noisy overtures, contemporary works with strong rhythmic vitality, even if, as was sometimes the case, of questionable worth. Most of the audience for the new music is recruited from the existing concert audience. One should encourage anything which will enlarge its ranks.

As to the larger problem of the arts in a mass society, I would say that the development of the American musical scene has been so totally different from anything which an earlier student of democratic culture could have predicted that we had best base our generalizations on empirical grounds. Alexis de Tocqueville's fear of a prevailing mediocrity in the arts makes no sense for concert music precisely because it does make sense for popular music, and popular music simply did not exist in his time: undoubtedly popular tastes corrupt the quality of our popular music (although even that has its defenders, notably Henry Pleasants), but the entire process serves to protect the concert music from corruption of any sort. It may be that popular and standard music serve as an artistic 
chastity belt to preserve the purity of our elite arts from the advances of tastes which would despoil them. But I think it more accurate to say that the popular audience is quite separate from the "elite" audience, and that when a listener makes the slow transition, he accepts fully what goes on in the concert hall. He in no sense corrupts concert music by his presence. If anything, he is liable at first to be too willing to con. form to accepted canons of behavior. We do know that people new to a class are the most concerned with propriety and the rules. Silas Lapham spends a whole chapter worrying about whether or not to wear those white gloves. Silas may be in the concert hall because he is a culturevulture; he may be impressed by radio announcers whose tones suggest that they are introducing music pressed on records of burnished gold; he may, in short, be coming to music for class reasons, and perhaps the chances are even good that he will never develop beyond his present state. But, to mix a few metaphors, he has ears, and may very well enlarge his tastes. Many of his fellows are at the base of our pyramid. We know at least this much about Cheops' pyramid: it was not built from the top down.

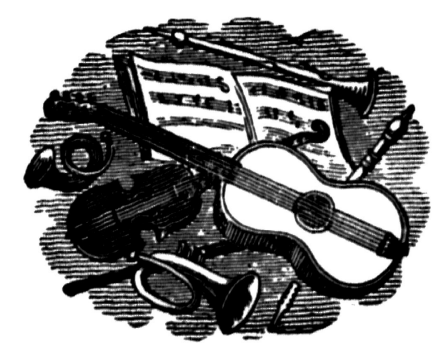

